\title{
Questing for Happiness: Augmenting Aristotle with Davidson?
}

\author{
Daniel D. Hutto, \\ University of Hertfordshire
}

\begin{abstract}
Drawing heavily on Aristotle, Tabensky attempts to establish 'an ethic that flows from the very structure of our being', but he also calls on Davidson's arguments about the essentially social character of rationality to shore up Aristotle's claim that we are essentially social beings. This much of his project, I argue is successful. However Tabensky takes this a step further and proposes a pluralist ethic on the grounds that a 'fully' or 'properly' instantiated account of the 'ideal' conditions for rationality requires encountering innumerable other points of view. Firstly, while confronting alternatives is essential to truth-seeking it hardly follows that an unconstrained pluralism represents an ideal condition for this kind of inquiry, since such an approach risks falling into mere clash of perspectives on practical grounds. Secondly, it is unclear how confronting more and more perspectives is supposed to help in enabling us to lead our lives well. In conclusion, picking up on this theme and looking again at Aristotle, I give reasons for questioning that the kind of rational choice involved in leading the good life, for reasons in part highlighted by Tabensky, benefits from analogy with the modes of conceptual rational inquiry in other domains in any case.
\end{abstract}

\section{Davidson and the Sociality Argument}

In a bid to revive the Ancient concern with a lived philosophy Tabensky sets out to make tenable his own version of an Aristotelian virtue ethic, one which places concern for eudaimonia and the living the good and happy life at its centre. In attempting to establish this as 'an ethic that flows from the very structure of our being', he draws on Davidson's holistic account of interpretation to shore up Aristotle's claims that we are essentially rational and, more particularly, social beings. This latter point is secured on the grounds that a capacity for intersubjective interpretation is a minimal condition for the very possibility of being rational and, concomitantly, being thinkers and speakers at all. The notions of objective truth and conceptual error only arise in the context of interpretation because it is only in recognizing the possibility of contrasting perspectives that one encounters the possibility of error. For reasons of space, I will not rehearse the details of this argument here as I have defended it at length elsewhere with a different agenda in mind (see Hutto 1999: 115-9). I am taking it for granted therefore that this much of Tabensky's project is successful.

Moreover, I agree with him that recognizing that our sociality is essential to our rationality - and thus our capacity to make assessments, evaluations and decisions at all has important consequences for the framing of the project of attempting to live well. We can see the importance of making the general contours of this project explicit to varying degrees by following the direction of Aristotle's own musings. He opens his treatise on ethics with a discussion of the nature of 'ends', distinguishing between those that are activities and those that are products of activities. With respect to the latter he observes 
that products are superior to the activities themselves in those cases in which the activity is simply a means to an end. Yet he also recognises that products themselves are generally created for further purposes so as to enable us to engage in other forms of activity. To use Aristotle's example, the art of bridle-making sub-serves the activity of riding horses, which can in turn sub-serve the activity of engaging military action, which we engage in for the purpose of achieving victory and so on. It is because ends can relate to one another in this instrumental way that we can order them in a hierarchy of importance.

These considerations provoke him to ask if there is some ultimate end for which everything else is done, for if there were not, "the process would go on to infinity, so that our desire would be empty and vain" (EN 1094 20-1). He concludes that virtuous activity itself, not some further product, is the only end which is complete and sought only for itself, unlike our more instrumental pursuits. As he observes, "no function of man has so much permanence as excellent activities" (EN $\left.1100^{\mathrm{b}} 13-4\right)$. Promotion of these in the lives of individuals is what brings ethics in line with politics. For him, politics is the most authoritative art because it dictates what is to be pursued and to what degree. As politics seeks to produce citizens of good character it is ultimately concerned with the proper development of individuals and the putting in place conditions under which they will prosper by creating an environment that aims to promote flourishing. In this way, "political science aims at what is the highest of all goods achievable by action" (EN 1095 15-6).

Aristotle labels this highest of all ends eudaimonia. Tabensky translates this as happiness, resisting the psychologistic reading. Other, but still imperfect, translations would be 'flourishing' or 'living well'. But what do any of these come to for human beings? Even in fourth century Athens the answers about the end of life differed. Aristotle tells us:

Verbally there is general agreement; for both the general run of men and people of superior refinement say that it is happiness, and identify living well and faring well with being happy; but with regard to what happiness is they differ, and many do not give the same account as the wise (EN $\left.1095^{\mathrm{a}} 16-21\right)$.

Establishing more precisely what constitutes living well is the first task of philosophical inquiry into ethics. ${ }^{1}$ Thus Aristotle enjoins:

...every one that has the power to live according to his own choice to set up for himself some object for the good life to aim at (whether honour or reputation or wealth or culture), with reference to which he will then do all his acts, since not to have one's life organised in view of some end is the mark of much folly (EE 1214 $\left.{ }^{\mathrm{b}} 6-11\right)$.

$1 \quad$ As Broadie observes, "The argument is designed so that it does not matter that no one has a clear idea of the nature of this end; a clear idea would obviate the need for Aristotle's philosophical inquiry” (Broadie 1991, p. 16). From a different angle, Haybron has argued that we will never have a sharply defined technical understanding of happiness in any case, as "the notion of happiness is not a theoretical concept at all” (Haybron 2003: 308). For reasons I will make clear shortly, I agree. 
Recognising that to be misled about which 'object for the good life' will best promote 'happiness' would have devastating effects for us, he asks, "Will not knowledge of it [the ultimate end], then, have a great influence on life” (EN 1094 22)? Given his teleological worldview, determining what it is for us to live well is necessarily tied to understanding our nature.

In his book Tabesnsky provides very convincing analyses which reveal how confusion on this score can upset one's chances of living well. Like Aristotle, he begins by criticising the most common response, which is to equate the good life with the life of pleasure. Their verdicts are similar in giving this idea short shrift and suggesting that once we bring out its true features it becomes clear that a life of pure pleasure-seeking is at best a life only suitable for beasts. This is because to give ourselves over to such a life in entirety would rob us of our capacity to make life choices and thus our capacity to lead a life, as opposed to merely living one. To strive to live thus would be in effect to place oneself willingly in Nozick's notorious experience machine, the consequences of which are set out in the third chapter of Anarchy, State and Utopia. It would be to surrender what sets us apart from the animals - what is 'peculiar to man' - our rational capacity. For the same reason, we must reject heroic speculations about how we might make ourselves more efficient for the purposes of information-processing, as the transformations suggested by some in this regard would, ironically, result in a kind of 'cognitive suicide', to borrow Baker's apt phrase (see Churchland 1989, Hutto 1999: ch. 7). This kind of confusion stems from forgetting that human beings belong to the genus: animal, differentia: rational. ${ }^{2}$

In showing why the lives of jellyfish and Gods are not for us, Tabensky uncovers a host of ways in which being mistaken about the conditions of personhood can fuel desires for kinds of life that would threaten the very possibility of leading a life at all by removing the possibility or motivation for the making of choices (Tabensky 2003: 1134). In this light, we can see why the Davidsonian reminder about our rational and social nature is so important. Nevertheless, getting clear about the basic conditions that make it possible to lead a life does not settle, in any substantive sense, (i) what the character such a life should have, or (ii) how 'unified' it must be, or (iii) what kind of unity it should have, if it is to flourish. Davidson's revelations about the essentially social character of thought and rationality at best show what is minimally required if we are to make the kinds of choices that are central to leading lives at all, but it leaves us with little real guidance about which life is most choiceworthy. I will return to this point in section 3 . Before doing so, I offer criticism of Tabensky's attempt to extend this basic line of thinking in support of pluralism.

\section{Pluralism: The Case Against}

Tabensky recognises that a consequence of Davidson's view on interpretation is that to be rational (even to have a thought) minimally requires recognition of the possibility of error - the possibility of perspectives on the world that contrast with one's own. Building on this insight Tabensky goes on to claim that a 'fully' or 'properly' instantiated account of the 'ideal' conditions for rationality requires more than the mere acknowledgement

2 Although Tabensky challenges the biological implications of this characterization as too restrictive, it does not affect the point at issue here (see Tabensky 2003: 19). 
that there can be other perspectives but instead should involve encounters with innumerable other points of views. Hence, he claims, "Davidson's minimal set-up can only be properly instantiated, as opposed to minimally instantiated, in the right sort of social environment” (Tabensky 2003: 134). Such an environment turns out to be robustly pluralist, since he claims exercising our rationality will best thrive if we are confronted with "radically different vantage points" (Tabensky 2003: 135). In light of this Davidsonian starting point, we might wonder just how radical these other perspectives can be, but more importantly we might wonder just how many other perspectives need to be confronted in order for us best to flourish. With respect to the latter, Tabensky speaks of our being aware of the possibility of 'inexaustable' number of alternative, yet finite perspectives, as a necessary ingredient in maintaining our well-developed sense of the world and truth.

To underline this idea, he presents Orwell's dystopia as diametrically opposed to his ideal, since it reduces all perspectives to a single one, that of Big Brother. Yet, interestingly, in the book the Party does not want to erode the very idea of truth, for the Ministry of Truth is bent on establishing their ever-shifting accounts as the truth. What it seeks to establish is that its pronouncements are to be only source of truth, putting them beyond question and challenge. ${ }^{3}$ Indeed, it is only against this background that Winston can still worry that, 'what was terrifying was not that they would kill you for thinking otherwise, but that they might be right' (emphasis mine).

It is perhaps more useful therefore to distinguish the conditions for the possibility of truth (thought and rationality) from the ideal conditions for establishing the truth. No one would argue that Oceania is not the place for the development of a thriving philosophical or scientific community. Still, it does not follow from this that the other extreme, a social environment that promotes radical pluralism would be either. Presumably, the quest for truth is best served not simply by confronting an endless stream of different perspectives, but by systematically challenging and reviewing claims; putting them under appropriate, targeted and careful pressure. While in practice conceptual progress requires the actual confrontation of other perspectives (and being appropriately alive to their potential challenge), this does take the form of encountering innumerable perspectives or in giving equal weight to each and all of them. To work such confrontations do not, and in practice could not, take the form of an unstructured or ungainly pluralism. It is by carefully distinguishing serious from implausible challengers, for the purpose of conducting specific debates that we ensure that in seeking to 'respect other perspectives' we do not fall into promoting mere clashes between them. Also, importantly, recognizing the potential fallibility of any given perspective, should not lead us to overlook the ever-present possibility that a current conception might be the correct one (and if so, then it should not be surrendered in favour of another). All of this is consistent with acknowledging that no matter how well established, all claims remain open to the possibility of challenge (Although the difference is subtle, this is not to say, as Quine does, that all claims are potentially revisable).

It is in that way that Orwell implies that 'the very existence of external reality was tacitly denied by their philosophy'. For the idea of an external reality is one that can only exist in an intersubjective space, where error is a live possibility, where claims are at least open to the possibility of being challenged. 
For these reasons, I am not persuaded by the attempt to extend Davidson's argument about our essential sociality to derive a pluralist ethic. Yet even if the case for pluralism could accommodate these criticisms, there is no reason to think that simply confronting a wealth of possibilities is what is really important to enabling us to live well as one might suppose by thinking that our chances of living the good life are increased if we have more and more possibilities to explore. We might think of this in terms of being able to make a wide range of important 'life choices' - picking this profession over that, choosing friends and partners, deciding where we should live, and so on. Certainly, we have more choice and freedom in this regard than our forefathers. But having to choose between countless 'live options' can be debilitating: indeed, it is potentially overwhelming (see Schwartz, 2004). As Tabensky himself observes when speculating about the plight of immortals, "one has no time to toy with inummerable other life options" (Tabensky 2003: 102). As our lives are limited there is a sense of urgency about living them well now - it is that activity, writ large, that should be our primary concern. Also, while important, making life choices of the kind just mentioned are not the most important ones in enabling us to live well, since they do not concern the habitual exercise of the virtues. That exercise concerns not only the particular challenges we face, but how we face them. In what follows, I want to give some consideration to what is involved in that practical project for it will reveal how distant it is to conceptual inquiry in any case.

\section{End without Theory, Practice without System}

There are stronger and weaker ways of reading Aristotle's injunction that to lead the good life one must, "have one's life organized in view of some end" (EE 1214 $\left.{ }^{\mathrm{b}} 11\right)$. In places, Tabensky speaks of theories, networks and systems and of maximizing their consistency or unity in a way that appears to draw heavily on analogies with idealised conceptual structures and inter-relations. For example, he writes:

It follows that one cannot properly understand the virtues either in isolation from one another or in isolation from a relatively complete theory of the good life, understood as the highest manifestation of the rational life (Tabensky 2003: 81, emphasis mine)

It follows that one can only properly understand the individual virtues within the framework of complete virtue and the role complete virtue plays within the system that constitutes a eudaimon life (Tabensky 2003: 81, emphasis mine).

Yet within the space of a page, Tabensky himself presents us with a clearly antitheoretical vision of how we must approach ethical concerns. He draws a useful analogy between painting and leading a life of virtue (Tabensky 2003: 28ff.). Great painters typically do not have clearly worked out conceptions of their subjects at the start of their endeavors, even if they aim to produce a work of art (perhaps even one that would fall into a particular category or movement). Despite this, the production of great art is not an aimless or haphazard business. Rather artists tend to have, "a rough and provisional conception of the telos" (Tabensky 2003: 29). They are effectively engaged in a MacIntyrean quest, for:

Without a partly determinate conception of the final telos there could not be any beginning to a quest ... but ...it is clear that the medieval conception of a quest is not at all a search for something already adequately characterised, as miners search for gold or 
geologists for oil. It is in the course of the quest and only through encountering and coping with the various harms, dangers, episodes and incidents that the goal of the quest is finally to be understood (MacInytre 1984: 219)

Nor do artists follow manuals or rulebooks in creating their art and in making decisions how to balance their composition or choosing when and where to make their brushstrokes.

Moral expertise is like artistry in both these respects. Just as there is no theory of the good life, so too the unity and coherence of the virtues is not something that can be understood in the form of an abstract template - rather it is something that is manifested in and through one's modus vivendi, by prosecuting a balancing act enables us to make the kinds of choices that bring the virtues into play appropriately - especially in those cases in which they pull against one another. To achieve this is to live the good life - but it is not a matter of conforming to 'a system'. Tabensky is well aware that each of us faces our own conflicts and circumstances and it is relation to these and these alone - in the concrete activity of the leading of our lives - that talk of the coherence of the virtues, which are essential practical, even makes sense. Abstract talk of the 'ideal' relations between the virtues is by comparison empty. Determining their proper relations demands a context.

It is no accident then that the bulk of the Nicomachean Ethics is concerned with the practical exercise of virtue: it is not a deductive work that descends from first principles, but is more of a dialectical inquiry into the nature of happiness or human well being, as these play out in our lives. As Reeve suggests, it is a work in nascent ethics; a dialectic to, not from, first principles (Reeve 1995: 32). However, I will shortly claim that its aim remains rooted in the practical throughout - it is never intended to generate first principles of the sort we might find in other sciences.

For example, its emphasis on what is 'achievable by action' is tied to Aristotle's critique of Plato's theory of forms, which he condemns for making ethical inquiry into 'an uphill struggle', famously excusing this slight on the grounds that a philosopher's piety requires us to, "honour truth above our friends" $\left(E N 1096^{\mathrm{a}} 16\right)$. As with many other important philosophical concepts, he observes that 'good' is polysemic. We call things good that are both substances, such as God or reason, and accidents, such as the virtues (in the case of quality) and moderation (in the case of quantity). Substances, for him, are prior to accidental properties, as when we compare a relationship of identity per se to that of the relation between the accidental properties of 'being bigger' or 'being smaller'. The point is that if some forms of goodness are 'accidents' then there can be no single form or understanding of the good that will meaningfully apply to all cases, anymore than there can be an abstract, non-relative notion of properties of bigness and smallness. He maintains that we can infer from these considerations that, "The good, therefore, is not something common answering to one Idea” (EN 1096 $\left.{ }^{\mathrm{b}} 25-6\right)$. He concludes, "clearly the good cannot be something universally present in all cases and single; for then it would not be predicated in all the categories but in one only" $\left(E N 1096^{\mathrm{a}} 28-30\right){ }^{4}$

We might wonder: Why all these different activities should be classed as Good? Aristotle briefly suggests that we might make such a single classification by analogy (in the same way that we talk of seeing with the eye and seeing with respect to reason). But he quickly drops this discussion on the grounds that seeking such exactness is better suited to other domains of inquiry. 
Furthermore, he claims that if there were only one idea of the good then there should be only one science of the good and this is manifestly untrue. We know that what is good for living beings varies from creature to creature. Aristotle cannot make any sense of the idea of pursuing 'the good' apart from pursuing one or other of its various parochial forms, relative to specific types of creatures and in our case particular individuals. By living well we conspire to bring about the good for us, which is achieved in a variety of ways.

Crucially then, living well does not depend on our having a theoretical understanding of the virtues: It requires an acquired taste for acting in accord with virtue and the practical wisdom to know how to do this when faced with certain choices. The first stems from having the right initial training. In order to benefit from ethical inquiry one must develop good basic habits and appropriate emotional responses. ${ }^{5}$ It is not required that one have the capacity to fully articulate what this involves or aims at. One must know how to act: to be moved to do so in the right ways, on the right occasions - engendering the appropriate responses. This is not the same as knowing why one should so act. It is open to challenge this reading on the grounds that knowledge appears as one of Aristotle's three conditions for having moral excellence, the other two being that (i) one must choose to acts virtuously (and choose to do so for sake of acting virtuously) and that (ii) the action must proceed from a firm and unchangeable character.

Even so, after proposing these conditions he goes on to tells us that the first counts for little, while the second and third count for nearly everything. Thus, while knowledge of why we should act virtuously is not unimportant, obtaining such knowledge is not the focus of ethical enquiry. In other words, its purpose is not theoretical. With this in mind, he criticises, "most people....[who] take refuge in theory and think they are being philosophers and will become good in this way....[noting that] the former will not be made well in soul by such a course of philosophy" (EN $\left.1105^{\mathrm{b}} 13-7\right)$. He stresses that, "we are inquiring not to know what excellence is but in order to become good" (EN $1103^{\mathrm{b}} 28$ 9). Simply knowing what is good for us is not enough: this knowledge must be practically deployed in leading our lives. And knowing only that the end of life is living virtuously or living well (as opposed to living a life of brute pleasure) will not aid us in actually exercising the virtues or making important life choices.

He maintains that, "excellences we get by first exercising them...for the things we have to learn before we do, we learn by doing" (EN $\left.1103^{\mathrm{a}} 31-2\right)$. Thus, "by doing the acts we do in our transactions with other men we become just or unjust" (EN 1103 $\left.{ }^{\mathrm{b}} 14-5\right)$. In other words, it is through the course of habit that we develop our characters because, “states arise out of like activities" (EN $\left.1103^{\mathrm{b}} 21\right)$. It this way, Aristotle's understanding of ethical practice is diametrically opposed to the intellectualist trend of much of today's analytic moral philosophy. Burnyeat describes this opposition well:

Intellectualism, a one-sided preoccupation with reason and reasoning, is a perennial failing in moral philosophy. The very subject of moral philosophy is sometimes defined or delimited as the study of moral reasoning, thereby excluding the moral development of the person. Aristotle knew intellectualism in the form of Socrates' doctrine that virtue is

We are told that, "it is plain that none of the moral excellences arises in us by nature; for nothing that exists by nature can form a habit contrary to nature” (EN $\left.1103^{\mathrm{a}} 19-21\right)$. Thus stones cannot acquire the habit of going upwards. Ethical development is thus unnatural if compared to, say, the way in which the senses actualize their potentiality without any training. 
knowledge. He reacted by emphasising the importance of beginnings and the gradual development of good habits of feeling (Burnyeat 1980: 70).

Since acting virtuously is a choice it is rooted in our motivations. Thus moral excellence is unavoidably tied up with our emotional responses and our animal natures our base tendencies to seek pleasure and avoid pain. We are told that is in response to pleasures and pains that we become bad, by pursuing and avoiding: those they ought not; when they ought not; and as they ought not. ${ }^{6}$ Against this, "excellence tends to do what is best with regard to pleasures and pains" (EN $\left.1104^{\mathrm{b}} 26-8\right)$. This is why Aristotle stresses that "our whole inquiry must be about these - to feel delight and pain rightly or wrongly has no small affect on our actions" (EN $\left.1105^{\mathrm{a}} 5-7\right) .{ }^{7}$ It is also why, in discussing virtues such as bravery, he emphasizes the connection between virtue and proper emotion, saying, "he who stands his ground against things that are terrible and delights in this (or at least is not pained) is brave, while a man who is pained is a coward" (EN 1104 ${ }^{\mathrm{a}}$ 19-22). On this account we become virtuous by habituating ourselves with respect to our passions so as, "to feel them at the right times, with reference to the right objects, towards the right people, with the right aim, and in the right way, is what is both intermediate and best, and this is characteristic of excellence" (EN 1106 $\left.{ }^{\mathrm{b}} 21-4\right){ }^{8}$

Our capacity to choose freely thus stems from fostering the right habits and acting virtuously involves, inter alia, performing the act with the right spirit or emotion. It is only by appeal to a person's steadfast character (bound up with their cultivated emotional responses) that we can understand the distinction between performing an act of a just character and acting justly. Urmson makes the connection clear.

We can readily imagine a situation in which the bad man, the self-controlled man, and the good man all act in the same way. If this is so, it can only be that the bad man is externally compelled to act that way - otherwise he would act differently. The selfcontrolled man will make himself act that way. Neither of them wants to act that way, neither likes acting that way, neither enjoys acting in that way, neither takes pleasure in acting in that way. But the good man is, without friction, manifesting and responding to his emotion. So he does it, liking it, wanting to, enjoying it, and taking pleasure in it (Urmson 1980: 159).

It should be clear by now that 'being virtuous' is practical activity on the part of individuals. But there is little general advice to be had on how that activity is to be

For example, as Burnyeat observes, Aristotle's approach allows us to make sense of how it is possible to take pleasure in something good but doing so in the wrong way. He gives these examples: "enjoying philosophy for the sense of power it can give, enjoying a trip abroad because of the splendid photographs you are taking, enjoying a party because you are meeting important people” (Burnyeat 1980: 76).

$7 \quad$ Kosman tells us, “Aristotle's more detailed discussions of the virtues make it clear that it is with respect to how one feels and not simply how one acts in light of one's feelings that one is said to be virtuous” (Kosman 1980: 108).

This is yet another reason why we are not simply seeking theoretical knowledge when making enquiries into ethics. We must develop a practical desire - a taste - for acting virtuously, but this involves more than merely a theoretical understanding of the pleasures this involves, as in the contrast between learning that "skiing is enjoyable" by hearsay as opposed to learning this by engaging in the activity itself (cf. Burnyeat 1980: 76). 
carried out. There is no more fixity in matters of ethics than in matters of health, which is consistent with Aristotle's general view on the exactness of the various sciences and in particular with those that deal with natural entities. ${ }^{9}$ As with matters concerning health, in which a doctor must know your particular case history before prescribing treatment in this domain too we are concerned with the practical application of knowledge in particular cases that are relative to the character and lives of specific individuals. This is quite unlike deploying purely theoretical knowledge. There is simply no recipe or general formula for ethical success. This is why the whole account must be given in outline and not precisely.

It is no accident that the best that Aristotle can offer is a rough characteristation of the proper end of life, cast as the activity of living well or 'happily'. In the main, he shows what the good life does not consist in and provides attendant advice on which virtues to develop, along with basic tips on how to do so in practice. Famously, we told that it is the nature of virtue to be destroyed by deviation from the mean much as health is perturbed by too little or too much food. Accordingly, a virtuous response is 'the equal as intermediate between excess and defect' (EN 1106 ${ }^{\mathrm{a}}$ 27-8). When we exhibit a moral excellence such as courage or friendliness, we walk a tightrope - always beset by the risk of falling into rashness or cowardice, on the one hand, or unpleasantness or obsequiousness, on the other.

Aristotle never gives us a more precise or more universal account of how the virtues are to be applied in relation to the mean because deciding on an appropriate action is relative to each of us (taking stock of our individual characters) and is always relative to circumstances. ${ }^{10}$ And because of this the 'mean' cannot be understood as an injunction to always behave moderately - for it is easy enough to see that in some circumstances extreme responses are warranted, in others not. It may be appropriate to violently subdue someone in one instance even if in another this same action would appear to be an overreaction (cf. Urmson 1980: 162). Consequently, the doctrine of the mean must not be

For the subject matter dictates exactness of discussion. And Aristotle's general view is that we can only have exact 'scientific' knowledge in the areas of mathematics and theology. His reason for thinking this connects with his views on matter/form relationships, and moreover it is such relationships which serve to explain why there is inexactitude in all other sciences other than the two just mentioned. The reasoning is that the objects of mathematics and theology are not enmattered - they are purely formal. Our understanding of number, for example is not bound to particular kinds of things, or any particular kind of thing. Thus, we can inquire into the nature of numbers by employing any kind of enmattered substances. On the other hand, the subject matter of most other sciences is to do with things that find their forms realised in matter. But Aristotle claims that such a union is rarely perfect nor is it all of a single kind. This is so for two reasons. Firstly, matter may resist the imposition of form, thought this way of putting things is somewhat awkward, and it overlooks the some of the subtleties of Aristotle's account. Secondly, more than one kind of matter may realise a particular form (at least in artefacts). Thus, there is a kind of hypothetical form to such realizations: they are means to end. For these reasons combined we find that with enmattered things the form is realised by degrees - or as Aristotle puts it "by the more or the less" (PA 644 14-15, cf. Reeve, 1995: 17-22). Since we are of the class of enmattered substances it is not possible to have absolute knowledge about human nature.

10 He offers further practical advice on how to behave virtuously, warning us to pull hard against our known inclinations towards one or the other form of excess. He recognizes that because it is not easy to hit the mean perfectly and because often one of deviant vices will be worse the other, it is better that we opt for the lesser of two evils. 
confused with maxim 'all things in moderation', though some readers make this mistake. ${ }^{11}$

Ultimately, the only advice Aristotle can give with regard to the exercise of moral excellence is that in trying to hit the mean, which lies relative to us, we should follow the example of the person of practical wisdom. Although a general understanding of the virtues is possible, there is no way to make the advice on how to order our activities more concrete, for living well involves making choices appropriate to particular lives and they must stem from our own uniquely established characters. If Aristotle is right, it should now be clear that the sense in which leading the good life involves 'maximising consistency' in line with an ideal of unity, cannot presuppose bringing our actions in line with a well worked out schema or theory.

\section{Conclusion}

If we stick with Tabensky's painter analogy, as we ought, leading the good life is not to living in accord with a general template, but it is making the 'best' of circumstances faced in our unique history during our particular trajectory through the world. It should be clear that purpose of inquiries into the good life are significantly unlike those we engaged in when concerned with more straightforward forms of conceptual inquiry. Living well is a practical business in which we often can do better than to ask: what would a phronimos do in our situation, if they had our peculiar aims and concerns? At best, we can look for guidance from exemplars of lives well lived - exemplars and not models are called for precisely because none of us will ever face quite the same challenges or live the same lives.

Relating all this back to Tabensky's remarks about pluralism, it is a vital condition for leading the good life is that we remain open to criticism, especially as we are prone to self-deception about our reasons. Although this might appear to echo what is minimally required for the pursuit of conceptual truth, it should be clear that in these cases what is required in not simply the confrontation of many 'alternative' perspectives. Rather to be of use in shaping our lives we need the kind of targeted advice and criticism that responds to our particular goals, concerns and past actions - criticism that is sensitive to our character and purpose. ${ }^{12}$ Acting as mirrors for us, virtue friends are best placed to provide this because of they know of the unique paths each of our lives take. This is why Aristotle regards them as ineliminable ingredient in aiding us in our quest for the good life.

11 Moreover, that it should not be so interpreted is evident from Aristotle's requirement that one ought to be 'properly affected' in the right circumstances.

12 Jacquette offers the following summary of the important roles friendship plays in this regard, "By offering mutual assistance in achieving virtue, including mastering the will, setting positive examples for one another, instilling a sense of shame for real or imagined wrongdoing, and in these and other ways enabling each other to produce morally worthy actions, friend of virtue help their friends on the way to happiness in living a good life” (Jacquette 2001: 385). 


\section{References}

Aristotle. 1984. Ethica Eudemia in the Complete Works of Aristotle: The Revised Oxford Translation. Edited by J. Barnes. New Jersey: Princeton University Press.

- 1984. Ethica Nichomachea in the Complete Works of Aristotle: The Revised Oxford Translation. Edited by J. Barnes. New Jersey: Princeton University Press.

Broadie, S. 1991. Ethics with Aristotle. Oxford: Oxford University Press.

Burnyeat, M.F. 1980. “Aristotle on Learning to Be Good.” In Essays on Aristotle's Ethics, edited by Amelie O. Rorty. Berkeley and Los Angeles: University of California Press.

Haybron, Daniel. 2003. "What Do We Want from a Theory of Happiness?” Metaphilosophy 34 (3) 305-29.

Hutto, Daniel. 2000. Beyond Physicalism. Amsterdam: John Benjamins.

Hutto, Daniel D. 1999. The Presence of Mind. Amsterdam: John Benjamins.

Jacquette, Dale. 2001. "Aristotle on the Value of Friendship as a Motivation for Morality.” Journal of Value Inquiry 35. 371-89.

Kosman, L.A. 1980. "Being Properly Affected: Virtues and Feelings in Aristotle's Ethics.” In Essays on Aristotle's Ethics, edited by Amelie O. Rorty. Berkeley and Los Angeles: University of California Press.

Nozick, Robert. 1977. Anarchy, State and Utopia. Oxford: Blackwell.

Reeve, C.D.C. 1995. Practices of Reason: Aristotle's Nicomachean Ethics. Oxford: Oxford University Press.

Schwartz, B. 2004. The Paradox of Choice. New York: Harpercollins.

Tabensky, Pedro A. 2003. Happiness: Personhood, Community, Purpose. Aldershot/Burlington: Ashgate.

Urmson, J.O. 1973/1980. “Aristotle's Doctrine of the Mean.” In Essays on Aristotle's Ethics, edited by Amelie O. Rorty. Berkeley and Los Angeles: University of California Press. 
Notes 